\title{
Aryl hydrocarbon receptor (AHR)-regulated transcriptomic changes in rats sensitive or resistant to major dioxin toxicities
}

\author{
Ivy D Moffat ${ }^{1}$, Paul C Boutros ${ }^{4}$, Hanbo Chen ${ }^{4}$, Allan B Okey ${ }^{1}$ and Raimo Pohjanvirta*2,3
}

\begin{abstract}
Background: The major toxic effects of 2,3,7,8-tetrachlorodibenzo-p-dioxin (TCDD) appear to result from dysregulation of mRNA levels mediated by the aryl hydrocarbon receptor (AHR). Dioxin-like chemicals alter expression of numerous genes in liver, but it remains unknown which lie in pathways leading to major toxicities such as hepatotoxicity, wasting and lethality. To identify genes involved in these responses we exploited a rat genetic model. Rats expressing an AHR splice-variant lacking a portion of the transactivation domain are highly resistant to dioxininduced toxicities. We examined changes in hepatic mRNA abundances 19 hours after TCDD treatment in two dioxinresistant rat strains/lines and two dioxin-sensitive rat strains/lines.
\end{abstract}

Results: Resistant rat strains/lines exhibited fewer transcriptional changes in response to TCDD than did rats with wildtype AHR. However, well-known AHR-regulated and dioxin-inducible genes such as CYP1A1, CYP1A2, and CYP1B1 remained fully responsive to TCDD in all strains/lines. Pathway analysis indicated that the genes which respond differently to TCDD between sensitive and resistant rats are mainly involved in lipid metabolism, cellular membrane function and energy metabolism. These pathways previously have been shown to respond differently to dioxin treatment in dioxin-sensitive versus dioxin-resistant rats at a biochemical level and in the differential phenotype of toxicologic responses.

Conclusion: The transactivation-domain deletion in dioxin-resistant rats does not abolish global AHR transactivational activity but selectively interferes with expression of subsets of genes that are candidates to mediate or protect from major dioxin toxicities such as hepatotoxicity, wasting and death.

\section{Background}

Dioxin-like chemicals are exceptionally toxic to a wide variety of birds, fish and mammals including, perhaps, humans. However, susceptibility to dioxin toxicity varies widely among different animal species and between genetic types within a species. Extensive evidence demonstrates that virtually all toxic effects of TCDD and related dioxin-like compounds are mediated by a liganddependent transcription factor, the aryl hydrocarbon receptor (AHR) (reviewed in: [1]). Exposure to dioxins results in major toxicities, including thymic atrophy, teratogenesis, hepatotoxicity, wasting syndrome and death. These toxicities are dependent on both the AHR

* Correspondence: raimo.pohjanvirta@helsinki.fi

2 Department of Food Hygiene and Environmental Health, Faculty of Veterinary Medicine, University of Helsinki, Helsinki, Finland

Full list of author information is available at the end of the article and its dimerization partner, the aryl hydrocarbon receptor nuclear translocator (ARNT), and require that the AHR have functional structures for nuclear translocation and DNA binding [2-6].

Dioxin binding converts the AHR into an activated ligand:AHR:ARNT complex that regulates transcription either by binding directly to AHRE-I motifs (also known as DREs or XREs) [7-10] or indirectly to AHRE-II motifs $[11,12]$. Dioxin toxicities appear to arise from AHR-mediated dysregulation of specific genes $[4,13]$. Microarray technologies have accelerated identification of genes that depend on the AHR for constitutive expression or for response to TCDD in vivo [14-23], but the key genes whose dysregulation by dioxin leads to most toxicities remain unknown.

The Han/Wistar(Kuopio) (H/W) rat is an excellent model organism to identify specific AHR-regulated genes 
whose dysregulation by dioxin may lead to major toxicities. $\mathrm{H} / \mathrm{W}$ rats are extraordinarily resistant to acute lethality from TCDD, with an $\mathrm{LD}_{50}$ three orders of magnitude higher than for sensitive Long-Evans(Turku/AB) rats (L-E) [24]. Resistance in H/W rats is associated with a point mutation that leads to expression of an aberrant AHR protein missing 38 or 43 amino acids from its transactivation domain (TAD) [25-27]. We recently demonstrated, using transgenic mouse models, that it is the AHR variant with 38 amino acids deleted that is responsible for dioxin resistance [28]. Importantly, this AHR variant is the predominantly-expressed form in the dioxinresistant $\mathrm{H} / \mathrm{W}$ rat [27]. Further, dioxin resistance in rats segregates genetically with the $A H R$ locus and is a dominant trait $[24,26]$. Multi-generational crosses of L-E and $\mathrm{H} / \mathrm{W}$ rats and selection for susceptibility or resistance to dioxin lethality [26] produced two rat lines: Line-A (LnA) and Line-C ( $\mathrm{LnC})$. LnA rats harbour the variant AHR and are dioxin-resistant; $\mathrm{LnC}$ rats have the wildtype AHR and are dioxin-sensitive. We postulate that the partial deletion of AHR transactivation domain alters toxic responses either by preventing changes in mRNA levels of genes in pro-death pathways or by enhancing responses of genes in pro-survival pathways.

Our strategy for identifying pro-survival or pro-death genes is to contrast changes in mRNA expression profiles following TCDD exposure of dioxin-sensitive and dioxinresistant rats [13]. To reduce the influence of strain-specific changes not associated with dioxin toxicities, we profiled 4 strains/lines of rats: $\mathrm{H} / \mathrm{W}$ and LnA which constitute the "resistant collective" and L-E and LnC which constitute the "sensitive collective".

We focused on hepatic mRNA levels because liver displays a broad spectrum of mRNAs that are responsive to dioxins and/or to $A H R$ genotype [20] and because liver is a prime site of dioxin toxicity, displaying many phenotypic differences between sensitive and resistant rats [29]. We chose a dose of $100 \mu \mathrm{g} / \mathrm{kg}$ TCDD, which produces hepatotoxicity, wasting and death in sensitive rats but no deaths in resistant rats. We previously conducted a smaller-scale transcriptomic study in sensitive versus resistant rats on membrane arrays and using cross-species hybridization to cDNA arrays [30]. Here, we greatly extend those prior studies by assessing transcriptomewide responses to TCDD which were further validated via real-time RT-PCR. We identify specific biological processes perturbed by TCDD exposure.

Our analysis paints a new picture of dioxin-induced expression changes. Hundreds of genes exhibit responses to TCDD that are specific to individual strains or lines. Our genetic model diminishes this background noise and identifies a small number of genes associated with hepatotoxicity, wasting and death. Genes differentiallyexpressed between sensitive and resistant strains show functional homogeneity: dioxin-lethality may be associated with broad dysregulation of entire pathways, not just single genes.

\section{Results}

To determine the effect of TCDD on mRNA abundances in dioxin-sensitive rats versus dioxin-resistant rats we studied four rat strains/lines at 19 hours after oral administration of TCDD (Figure 1) using Affymetrix RAE230A microarrays. A list of all genes and their responses to TCDD in the four rat strains/lines is given in Additional File 1 .

\section{Global differences in mRNA abundance}

The total number of genes affected by TCDD varied across rat strains/lines in a manner independent of the statistical threshold (Figure 2A). More genes were affected by TCDD in dioxin-sensitive rats than in dioxinresistant rats: across all four strains/lines, the order of the number of transcriptional alterations was: $\mathrm{L}-\mathrm{E}>\mathrm{LnC}>$ LnA > H/W. Overall, it appears that the deletion in the AHR transactivation domain reduces the number of genes altered but does not ablate the transcriptional response to TCDD.

Unsupervised clustering analysis (Figure 2B) using all non-constant genes (variance $>0.01$ ) revealed the strongest trend in the dataset was the distinction between TCDD-treated (red annotation bars) and vehicle-treated (white annotation bars) animals. The co-clustering of the two $\mathrm{F}_{2}$ crosses (LnA, dark blue; LnC, light blue) may indicate that their common parentage is a stronger determi-

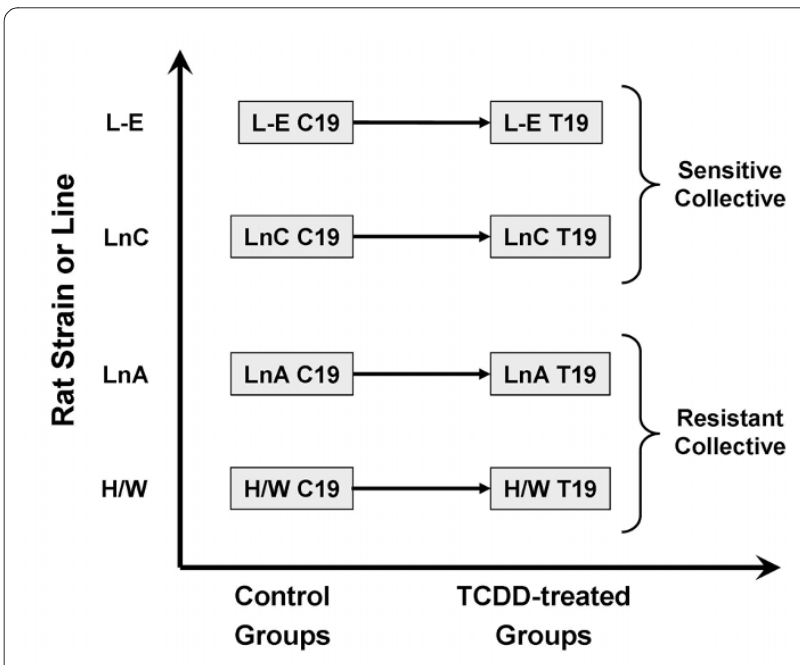

Figure 1 Experimental Design. A two-factor design was used to assess the effects of strain/line ( $L-E, L n C, L n A$ and $H / W$ ) and TCDD-exposure (control or 19-hour exposure to $100 \mu \mathrm{g} / \mathrm{kg}$ TCDD). In total 32 mRNA profiles were assessed by individual RAE230A microarrays; four separate animals were profiled for each of the eight separate experimental conditions. 
(A)

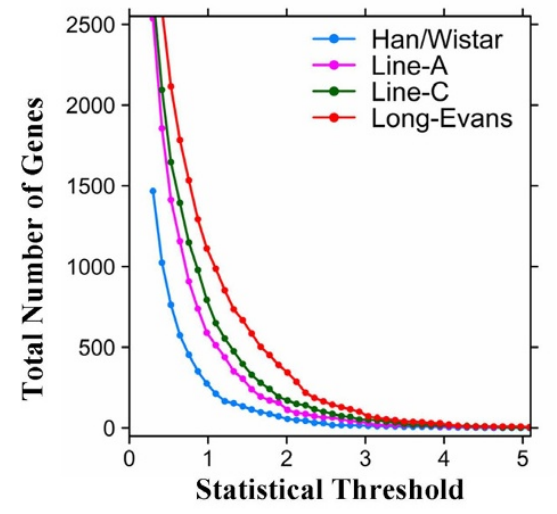

(B)

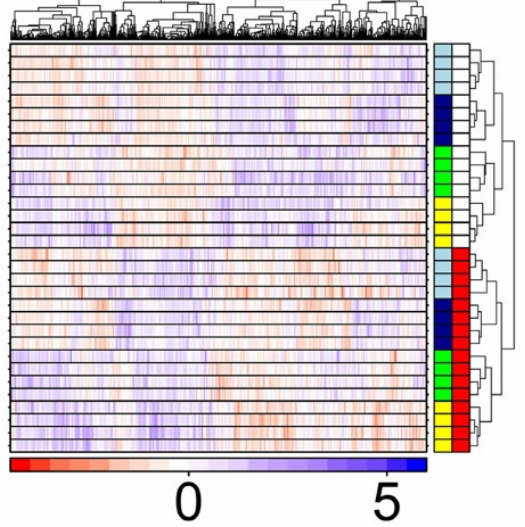

Figure 2 Global comparison of expression profiles between rat strains/lines. (A) The total number of genes affected by TCDD treatment in each rat line or strain is compared at levels of statistical significance (adjusted p-values; - $\log 10$ ) ranging from 0 to 5. (B) Hierarchical clustering with within-row scaling of all non-constant genes (variance $>0.1$ ). Within the heatmap, blue indicates genes induced (up-regulated) by TCDD; red indicates genes repressed (down-regulated) by TCDD. Within the annotation bars (right side of heatmap), red indicates which rats were exposed to TCDD and white indicates those exposed to corn oil vehicle. The first column of annotation bars indicates the strains/lines of animals profiled: yellow, L-E; light blue, LnC; green, H/W, dark blue, LnA. The colour-scale gives within-row-scaled expression values, with red hues indicating low-expression and blue hues indicating high-expression.

nant of their transcriptional profiles than is their sensitivity or resistance to TCDD toxicity. Further, this suggests that number of genes causally related to the hepatotoxicity (and possibly acute lethality) of TCDD is small compared with all other changes caused by TCDD in hepatic gene expression.

The extent of the overlap in transcriptional responses to TCDD among sensitive and resistant rat strains/lines was visualized using a two-way table (Table 1) and Venn diagrams (Figure 3). Of the 8605 genes interrogated, 452 $(5.3 \%)$ responded in at least one strain or line at a $1 \%$ false-discovery rate; 8153 genes did not respond to TCDD in any strain/line (Table 1). Of the 452 responsive genes only $144(31.9 \%)$ were altered in more than one strain/line. Only 25 genes responded in all strains/lines, of which 20 were induced while only 5 were genes repressed. This direction of response is concordant with our previous finding that $70 \%$ of genes altered in common by TCDD in both mouse and rat are up-regulated [23].

The sensitive collective exhibited a greater number of responsive genes (412) and a greater overlap of these genes among strains/lines within the collective (Figure 3A) than did the resistant collective (138 responsive genes; Figure $3 \mathrm{~B}$ ). However, the proportion of TCDDresponsive genes that overlapped within each collective to the total genes on the array that responded to TCDD in that collective did not differ between collectives $(22.5 \%$ in the resistant vs. $26.2 \%$ in the sensitive collective, $\mathrm{p}=0.44$; proportion test).

\section{Classification of Type-I vs. Type-II responses to TCDD}

Identifying which of the 452 TCDD-responsive genes are most likely to be involved in major dioxin toxicities is challenging; we therefore exploited our genetic model. Each TCDD-responsive gene was classified according to the Type-I/Type-II TCDD response scheme previously developed for toxic endpoints [31].

Type-I responses to TCDD are those that are similar between dioxin-sensitive rat strains/lines and dioxinresistant rat strains/lines. We considered genes that exhibited a statistically significant response to TCDD in all four strains/lines to be Type-I genes. By this definition 25 genes were classified as Type-I (Figure 3C; Score \pm 4 in Table 1). These Type-I genes include well-known (Table 2) as well as novel TCDD-responsive genes (Additional File 1 ). The vast majority of Type-I genes (20/25) were up-regulated by TCDD (score +4 in Table 1$)$. For some Type-I genes the magnitude of induction was very large, including $~ 90$-fold induction of CYP1A1 mRNA and 75-fold induction of $A L D H 3 A 1$ mRNA.

Type-II responses to TCDD are those that differ between dioxin-sensitive rats and dioxin-resistant rats. Genes that responded to TCDD exposure in a statistically significant manner in both members of one collective but neither of the strains/lines in the other collective are classified as Type-II genes. By this classification, 46 genes exhibited Type-II responses (Figure 3C; Score \pm 2 \& 0 in both ways in Table 1). Of these, only three were altered in resistant rats but not in sensitive rats (Il1r1, Phyh, Hacl1). The remaining 43 genes were specifically altered only in dioxin-sensitive rats. In contrast to the $80 \%$ upregulation of Type-I genes, 61\% (28/46) of Type-II genes were downregulated by TCDD. 
Table 1: Extent of overlap in transcript responses to TCDD among dioxin-sensitive and dioxin-resistant rat strains/lines

\begin{tabular}{|c|c|c|c|c|c|c|}
\hline & & \multicolumn{5}{|c|}{ Sensitive Collective Score } \\
\hline & & -2 & -1 & 0 & 1 & 2 \\
\hline \multirow{5}{*}{$\begin{array}{l}\text { Resistant } \\
\text { Collective } \\
\text { Score }\end{array}$} & -2 & 5 & 1 & 1 & 0 & 0 \\
\hline & -1 & 14 & 18 & 7 & 0 & 0 \\
\hline & 0 & 26 & 177 & 8153 & 94 & 17 \\
\hline & 1 & 0 & 0 & 30 & 12 & 26 \\
\hline & 2 & 0 & 0 & 2 & 2 & 20 \\
\hline \multicolumn{7}{|c|}{$\begin{array}{l}\text { To evaluate the overlap of significantly }\left(p_{\text {adjusted }}<0.01 \text { ) altered transcripts between the sensitive and resistant collectives we formed a two- }\right. \\
\text { way table. A TCDD-responsive score of }-1 \text { (repressed), } 0 \text { (unchanged), or }+1 \text { (induced) was assigned to each gene in each strain. The sum of } \\
\text { the scores for the sensitive strains/lines form the columns and the sum of the scores for the resistant strains/lines are the rows. Each value } \\
\text { corresponds to the number of genes that exhibited a significant response to TCDD treatment. For example, } 20 \text { genes are induced in both } \\
\text { sensitive and both resistant strains/lines, while } 5 \text { genes are repressed in both of the sensitive strains/lines and both of the resistant strains/ } \\
\text { lines. Of the } 8605 \text { genes examined, } 452 \text { genes responded in at least } 1 \text { strain/line, while } 8153 \text { genes did not respond to TCDD in any rat strain/ } \\
\text { line. }\end{array}$} \\
\hline
\end{tabular}

\section{Validation by real-time RT-PCR}

The validity of our array experiments to identify effects of TCDD on mRNA levels is supported by the facts that well-established dioxin-inducible genes were identified (e.g. CYP1A1, CYP1A2, CYP1B1 and Tiparp; Table 2) and there is overlap between our current list of responsive genes and genes previously reported to be affected by AHR-ligands in other array experiments $[15,17]$.

To further assess the validity of our array results we employed real-time RT-PCR to evaluate effects of TCDD on mRNA levels. Genes were selected for RT-PCR analysis to span a wide range of magnitudes of response (foldchange in $\log _{2}$ : high $>4$; medium $2-4$; low $<2$; or no response). To this end, both array (Table 2) and RT-PCR analyses (Figure 4) showed a high magnitude of TCDDmediated induction of the prototypical responsive/AHRactivated gene CYP1A1 [13,32,33]. Further, CYP7A1 and Chka exhibited medium magnitudes of response to TCDD in both collectives as evidenced by RT-PCR assays (Figure 4) as well as, array experiments (Additional File 1). Selenbp 1 and Per2 showed low magnitudes of TCDDmediated induction in both collectives as evidenced by array experiments (Additional File 1) and slightly higher magnitudes of induction by RT-PCR assays (Figure 4). Elov6 exhibited significant induction in the dioxin-sensitive collective but not in the resistant collective as assayed both by array (Table 3) and RT-PCR (Figure 4). TCDD had no significant effect on mRNA levels for Klf10 or
Pik3r1 as assayed either by RT-PCR (Figure 4) or by gene array (Additional File 1).

\section{Analysis of the AHR role in regulation}

It is well-established that major toxicities of TCDD require the AHR $[2,4,5,34,35]$. To determine if the AHR was required for the gene to respond to TCDD we compared hepatic mRNA levels for a few genes in $A h r$-null mice $\left(A h r^{/-}\right)$versus mice with wildtype AH receptor $\left(A h r^{+/+}\right)$. Mice were treated with a dose of TCDD equitoxic to that in sensitive rats [23] for a comparable time. As expected, induction of CYP1A1 mRNA was strictly dependent on the AHR (Figure 5). Suppression of Crip2 mRNA levels also was AHR-dependent (Figure 5). Regulation of Chka and Elovl6 by TCDD appears to be species-specific: Chka mRNA was upregulated in rats from both collectives (Additional File 1 and Figure 4) but was significantly downregulated in $A h r$-null mice and unaffected in wildtype mice (Figure 5); Elovl6 was upregulated in dioxin-sensitive rats (Table 3 and Figure 4) but Elovl6 was unresponsive to TCDD in both wildtype and Ahrnull mice (Figure 5). The findings with Chka and Elovl6 reinforce recent reports of substantial differences between rat and mouse in transcriptional responses to TCDD $[16,23]$.

\section{Pathway Analysis}

To determine if alterations in mRNA abundances caused by TCDD are functionally coherent, we performed two 
(A)

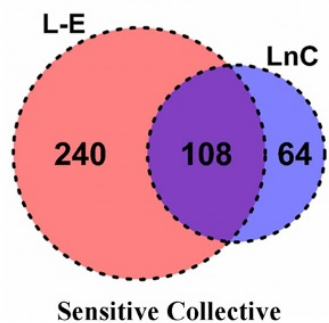

Sensitive Collective

(C)

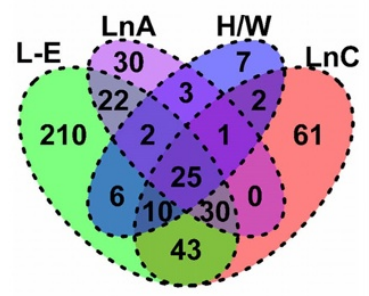

Figure 3 Overlap of altered transcripts between rat strains/lines We generated Venn diagrams to visualize the overlap of significantly ( $p_{\text {adjusted }}<0.01$ ) altered transcript responses to $100 \mu \mathrm{g} / \mathrm{kg}$ TCDD for 19 hours between the sensitive and resistant collectives: $(\mathbf{A})$ across the sensitive collective, (B) across the resistant collective and (C) across all four strains/lines.

Gene Ontology (GO) analyses. The first used candidate genes from each rat strain/line to determine the extent of overlap of pathways between rat strains/lines. We found that the pathways dysregulated by TCDD were very similar in the two dioxin-resistant rats, LnA and H/W (Figure 6A) and in the two dioxin-sensitive rats, $\mathrm{LnC}$ and $\mathrm{L}-\mathrm{E}$ (Figure 6B). Further, there was overlap in pathways among all strains/lines: $8 \mathrm{GO}$ terms were enriched in all four strains/lines, while $14 \mathrm{GO}$ terms were specifically enriched in only the sensitive strains (Figure 6C).

The second analysis used both Type-I and Type-II gene lists to determine the specific GO terms enriched in each of the Type-I and Type-II gene lists. This analysis identified 5 GO terms - mostly relating to cytochrome P450 genes - enriched in the Type-I genes (Table 4). Amongst the Type-II genes, the analysis identified 14 GO terms specifically enriched (Table 4). In particular, genes related to the endoplasmic reticulum were present about 4 times as often as expected by chance alone, as were genes related to lipid metabolism.

\section{Discussion}

We performed transcriptional profiling on livers of rats that are sensitive or resistant to major TCDD toxicities. Two key findings arise. First, we show significant interstrain and inter-species diversity in responses to TCDD.
Second, we identify Type-II genes that may be integral to the mechanism(s) of hepatotoxicity, wasting and lethality.

\section{Significant diversity of intra-species and inter-species responses to TCDD}

One startling characteristic of the transcriptional response to TCDD across the four rat strains/lines are the dramatic inter-strain differences. Given their substantial genetic relatedness, including at the $A H R$ locus, it might be hypothesized that LnA and H/W animals would have very similar responses, and that $\mathrm{LnC}$ would be very similar to L-E. To the contrary, 68.1\% (308 of 452) of dioxinresponsive genes were altered in one of the four rat strains/lines. These results clearly demonstrate the importance of genomic context in regulating mRNA responses to dioxin-exposure and mirror an analysis of the basal mRNA levels in these and other rat strains (Boutros et al. submitted). Interestingly, in rats with the $A H R^{\mathrm{H} / \mathrm{W}}$ genotype, the total number of genes that respond was reduced relative to rats expressing wildtype AHR. However, AHRs from rats with the $A H R^{\mathrm{H} / \mathrm{W}}$ genotype have similar affinity for TCDD and ability to bind $\mathrm{AH}$ response elements as wildtype rats [36]. It is conceivable that $A H R^{\mathrm{H} / \mathrm{W}}$ rats have a reduced ability to recruit coactivators and interact with transcriptional machinery. Chromatin immuno-precipitation experiments would be valuable in testing this hypothesis directly.

When we attempted to study AHR-dependency of the mRNA changes by comparison with $A h r^{-1-}$ mice we found that only 2 of 4 mRNA responses to TCDD, measured by RT-PCR, could be compared in both rat and mouse models. This result concords with recent reports of highly divergent transcriptomic responses to TCDD between rat and mouse [23], and suggests that combining our intraspecies rat model with inter-species studies may be a fruitful approach for identifying genes that mediate TCDD-induced toxicities, especially those toxic responses that differ between animal species.

\section{Type-II responsive genes whose regulation by TCDD may be integral to the mechanism(s) of hepatotoxicity, wasting and lethality}

In dioxin-sensitive rats, a wasting syndrome commences within the first few days following a single dose of TCDD and is characterized by progressive weight loss (eventually up to 50\%) and hypophagia [37-39]. Wasting contributes to lethality starting 2-3 weeks after TCDD exposure. Although wasting accompanies death, wasting per se is not likely to be the sole reason for death since maintenance of body weight by parenteral nutrition does not prevent mortality [40]. Nevertheless, untreated control rats, pair-fed at the same caloric intake as rats treated with lethal TCDD doses, die at much the same time as their TCDD-exposed partners [41]. 
Table 2: Known dioxin-inducible genes

\begin{tabular}{|c|c|c|c|c|c|c|c|c|c|c|}
\hline \multicolumn{4}{|c|}{ Resistant Collective } & \multicolumn{4}{|c|}{ Sensitive Collective } & \multirow[b]{3}{*}{ Gene ID } & \multirow[b]{3}{*}{ Symbol } & \multirow[b]{3}{*}{ Full Name } \\
\hline \multicolumn{2}{|c|}{$H / W$} & \multicolumn{2}{|c|}{$\operatorname{Ln} A$} & \multicolumn{2}{|c|}{ L-E } & \multicolumn{2}{|c|}{$\operatorname{LnC}$} & & & \\
\hline FC log2 & padj & FC log2 & padj & FC $\log 2$ & padj & FC $\log 2$ & padj & & & \\
\hline 6.3 & $3.2 \times 10^{-9}$ & 5.4 & $8.2 \times 10^{-8}$ & 6.8 & $2.2 \times 10^{-12}$ & 6.2 & $8.9 \times 10^{-10}$ & 25375 & Aldh $3 a 1$ & $\begin{array}{l}\text { aldehyde } \\
\text { dehydrogenase } 3 \text { family, } \\
\text { member A1 }\end{array}$ \\
\hline 6.4 & $1.3 \times 10^{-4}$ & 6.1 & $1.0 \times 10^{-6}$ & 6.6 & $3.3 \times 10^{-8}$ & 6.4 & $1.8 \times 10^{-9}$ & 24296 & Сyp1a1 & $\begin{array}{l}\text { cytochrome P450, } \\
\text { family } 1 \text {, subfamily a, } \\
\text { polypeptide } 1\end{array}$ \\
\hline 1.2 & $2.0 \times 10^{-5}$ & 1.2 & $1.6 \times 10^{-5}$ & 1.1 & $1.5 \times 10^{-6}$ & 1.1 & $1.9 \times 10^{-5}$ & 24297 & Cyp1a2 & $\begin{array}{l}\text { cytochrome P450, } \\
\text { family } 1 \text {, subfamily a, } \\
\text { polypeptide } 2\end{array}$ \\
\hline 3.9 & $6.8 \times 10^{-5}$ & 3.5 & $4.9 \times 10^{-7}$ & 5.3 & $4.4 \times 10^{-6}$ & 4.9 & $7.8 \times 10^{-6}$ & 25426 & Cyp1b1 & $\begin{array}{l}\text { cytochrome P450, } \\
\text { family } 1 \text {, subfamily b, } \\
\text { polypeptide } 1\end{array}$ \\
\hline 1.2 & $4.4 \times 10^{-3}$ & 1.1 & $1.9 \times 10^{-3}$ & 1.9 & $3.8 \times 10^{-4}$ & 1.4 & $1.9 \times 10^{-3}$ & 83619 & $\mathrm{Nfe} 212$ & $\begin{array}{l}\text { nuclear factor, erythroid } \\
\text { derived 2, like } 2\end{array}$ \\
\hline 3.7 & $3.2 \times 10^{-5}$ & 2.5 & $1.4 \times 10^{-4}$ & 2.4 & $4.9 \times 10^{-5}$ & 2.6 & $4.5 \times 10^{-5}$ & 24314 & Nqo1 & $\begin{array}{l}\mathrm{NAD}(\mathrm{P}) \mathrm{H} \\
\text { dehydrogenase, } \\
\text { quinone } 1\end{array}$ \\
\hline 2.3 & $1.2 \times 10^{-3}$ & 1.8 & $1.3 \times 10^{-3}$ & 2.5 & $1.6 \times 10^{-4}$ & 2.2 & $1.7 \times 10^{-4}$ & 310467 & Tiparp & $\begin{array}{l}\text { TCDD-inducible } \\
\text { poly(ADP-ribose) } \\
\text { polymerase }\end{array}$ \\
\hline
\end{tabular}

Transcriptional responses after 19-hour TCDD exposure in the four rat strains/lines were identified using Affymetrix RAE230A arrays followed by data pre-processing and statistical testing using linear models. Twenty-five Type-I genes (similar response to TCDD in all four strains/lines) were identified. These included several well-established AHR-regulated and dioxin-inducible genes, supporting the validity of the array experiments. For each strain/line, the fold-change ( $F C$ in $\log _{2}$ space) in mRNA levels between treated and control rats as well as the significance levels are presented. 
Table 3: Type-II gene responses 19 hours after TCDD exposure

\begin{tabular}{|c|c|c|c|c|c|c|c|c|c|c|}
\hline \multicolumn{4}{|c|}{ Resistant Collective } & \multicolumn{4}{|c|}{ Sensitive Collective } & \multirow[b]{3}{*}{ Gene ID } & \multirow[b]{3}{*}{ Symbol } & \multirow[b]{3}{*}{ Full Name } \\
\hline \multicolumn{2}{|c|}{$H / W$} & \multicolumn{2}{|c|}{$\operatorname{Ln} A$} & \multicolumn{2}{|c|}{ L-E } & \multicolumn{2}{|c|}{$\operatorname{LnC}$} & & & \\
\hline FC log2 & padj & FC log 2 & padj & FC log2 & padj & FC log2 & padj & & & \\
\hline-0.3 & $7.3 \times 10^{-2}$ & -0.4 & $1.1 \times 10^{-2}$ & -0.7 & $5.7 \times 10^{-4}$ & -0.3 & $3.0 \times 10^{-3}$ & 25368 & Adk & adenosine kinase \\
\hline 0.4 & $2.2 \times 10^{-2}$ & 0.2 & $5.6 \times 10^{-2}$ & 0.6 & $6.2 \times 10^{-3}$ & 0.4 & $4.8 \times 10^{-3}$ & 305338 & Apbb2 & $\begin{array}{l}\text { amyloid beta (A4) precursor protein- } \\
\text { binding, family B, member } 2\end{array}$ \\
\hline-0.4 & $1.4 \times 10^{-1}$ & -0.3 & $6.8 \times 10^{-2}$ & -0.8 & $1.5 \times 10^{-3}$ & -0.5 & $2.9 \times 10^{-3}$ & 25698 & Ass1 & argininosuccinate synthetase 1 \\
\hline 0.3 & $7.3 \times 10^{-2}$ & 0.4 & $1.1 \times 10^{-2}$ & 0.4 & $7.3 \times 10^{-3}$ & 0.4 & $1.4 \times 10^{-3}$ & 116550 & Atp5c1 & $\begin{array}{l}\text { ATP synthase, } \mathrm{H}+\text { transporting, } \\
\text { mitochondrial } \mathrm{F} 1 \text { complex, gamma } \\
\text { polypeptide } 1\end{array}$ \\
\hline-0.9 & $6.5 \times 10^{-2}$ & -0.6 & $4.8 \times 10^{-2}$ & -0.9 & $4.3 \times 10^{-3}$ & -0.8 & $4.5 \times 10^{-3}$ & 64828 & B4galnt1 & $\begin{array}{l}\text { beta-1,4-N-acetyl-galactosaminyl } \\
\text { transferase } 1\end{array}$ \\
\hline 0.3 & $1.6 \times 10^{-1}$ & 0.2 & $6.0 \times 10^{-2}$ & 0.6 & $4.3 \times 10^{-3}$ & 0.7 & $1.5 \times 10^{-3}$ & 113948 & Bbs2 & Bardet-Biedl syndrome 2 homolog (human) \\
\hline 0.3 & $3.0 \times 10^{-1}$ & 0.5 & $5.7 \times 10^{-2}$ & 0.5 & $1.0 \times 10^{-3}$ & 0.6 & $2.2 \times 10^{-3}$ & 292027 & $C f d p 1$ & craniofacial development protein 1 \\
\hline-0.2 & $2.3 \times 10^{-1}$ & -0.3 & $7.1 \times 10^{-2}$ & -0.6 & $1.0 \times 10^{-3}$ & -0.6 & $1.5 \times 10^{-3}$ & 85251 & Col18a1 & collagen, type XVIII, alpha 1 \\
\hline-0.3 & $3.2 \times 10^{-1}$ & -0.5 & $6.6 \times 10^{-2}$ & -0.9 & $1.7 \times 10^{-4}$ & -0.4 & $9.4 \times 10^{-3}$ & 266682 & Сурза2 & $\begin{array}{l}\text { cytochrome P450, family } 3 \text {, subfamily a, } \\
\text { polypeptide } 2\end{array}$ \\
\hline-0.4 & $2.8 \times 10^{-1}$ & -0.5 & $3.3 \times 10^{-2}$ & -0.9 & $7.8 \times 10^{-5}$ & -0.5 & $2.2 \times 10^{-3}$ & 286904 & Cyp4f4 & $\begin{array}{l}\text { cytochrome } P 450 \text {, family } 4 \text {, subfamily } \mathrm{f} \text {, } \\
\text { polypeptide } 4\end{array}$ \\
\hline 0.4 & $1.2 \times 10^{-2}$ & 0.2 & $5.0 \times 10^{-2}$ & 0.4 & $1.2 \times 10^{-3}$ & 0.4 & $3.5 \times 10^{-3}$ & 362912 & Derl1 & Der1-like domain family, member 1 \\
\hline 0.6 & $6.6 \times 10^{-2}$ & 0.3 & $2.3 \times 10^{-2}$ & 0.6 & $1.7 \times 10^{-3}$ & 0.6 & $6.5 \times 10^{-4}$ & 691956 & Derl2 & Der1-like domain family, member 2 \\
\hline-0.4 & $1.5 \times 10^{-1}$ & -0.3 & $1.0 \times 10^{-1}$ & -0.4 & $5.9 \times 10^{-3}$ & -0.5 & $9.7 \times 10^{-3}$ & 25313 & Egf & epidermal growth factor \\
\hline 0.3 & $6.3 \times 10^{-1}$ & 1.1 & $2.0 \times 10^{-1}$ & 1.2 & $3.3 \times 10^{-4}$ & 0.6 & $9.8 \times 10^{-3}$ & 171402 & Elovi6 & $\begin{array}{l}\text { ELOVL family member } 6 \text {, elongation of long } \\
\text { chain fatty acids (yeast) }\end{array}$ \\
\hline-0.3 & $2.9 \times 10^{-1}$ & -0.3 & $7.2 \times 10^{-2}$ & -0.7 & $1.0 \times 10^{-3}$ & -0.5 & $9.4 \times 10^{-3}$ & 29580 & Fdft 1 & farnesyl diphosphate farnesyl transferase 1 \\
\hline-0.3 & $3.7 \times 10^{-1}$ & -0.3 & $4.3 \times 10^{-2}$ & -0.7 & $4.2 \times 10^{-4}$ & -0.4 & $4.1 \times 10^{-3}$ & 297029 & Gstk1 & glutathione S-transferase kappa 1 \\
\hline-0.5 & $9.3 \times 10^{-2}$ & -0.2 & $1.8 \times 10^{-1}$ & -0.7 & $6.9 \times 10^{-3}$ & -0.4 & $3.0 \times 10^{-3}$ & 81869 & Gstm7 & glutathione S-transferase, mu 7 \\
\hline-1.3 & $7.2 \times 10^{-3}$ & -1.0 & $1.1 \times 10^{-3}$ & -1.1 & $3.4 \times 10^{-2}$ & -1.2 & $1.2 \times 10^{-2}$ & 85255 & Hacl1 & 2-hydroxyacyl-CoA lyase 1 \\
\hline-0.2 & $6.3 \times 10^{-1}$ & -0.3 & $1.8 \times 10^{-1}$ & -0.7 & $6.5 \times 10^{-4}$ & -0.7 & $2.2 \times 10^{-3}$ & 24439 & Hagh & hydroxyacyl glutathione hydrolase \\
\hline-0.6 & $2.5 \times 10^{-2}$ & -0.2 & $2.1 \times 10^{-1}$ & -0.6 & $2.7 \times 10^{-3}$ & -0.7 & $4.7 \times 10^{-3}$ & 25116 & $H s d 11 b 1$ & hydroxysteroid 11-beta dehydrogenase 1 \\
\hline 0.5 & $1.5 \times 10^{-1}$ & 0.3 & $1.1 \times 10^{-1}$ & 0.9 & $1.0 \times 10^{-3}$ & 0.6 & $4.8 \times 10^{-3}$ & 84013 & Hsd17b12 & hydroxysteroid (17-beta) dehydrogenase 12 \\
\hline
\end{tabular}


Table 3: Type-II gene responses 19 hours after TCDD exposure (Continued)

\begin{tabular}{|c|c|c|c|c|c|c|c|c|c|c|}
\hline 1.4 & $5.1 \times 10^{-3}$ & 0.5 & $3.9 \times 10^{-3}$ & 0.7 & $4.3 \times 10^{-2}$ & 0.9 & $1.5 \times 10^{-2}$ & 25663 & $\| 11 r 1$ & interleukin 1 receptor, type I \\
\hline-0.6 & $3.7 \times 10^{-2}$ & -0.3 & $1.8 \times 10^{-1}$ & -0.7 & $3.8 \times 10^{-3}$ & -0.8 & $6.1 \times 10^{-4}$ & 690745 & LOC690745 & $\begin{array}{l}\text { MOCO sulphurase C-terminal domain } \\
\text { containing-like }\end{array}$ \\
\hline 0.2 & $8.5 \times 10^{-1}$ & -0.5 & $4.2 \times 10^{-2}$ & -0.8 & $8.5 \times 10^{-4}$ & -0.5 & $4.8 \times 10^{-3}$ & 497794 & Mug1 & murinoglobulin 1 \\
\hline-0.4 & $8.6 \times 10^{-2}$ & -0.4 & $4.1 \times 10^{-2}$ & -0.6 & $3.6 \times 10^{-3}$ & -0.6 & $8.6 \times 10^{-3}$ & 29227 & Nfib & nuclear factor I/B \\
\hline-0.5 & $9.3 \times 10^{-2}$ & -0.6 & $3.2 \times 10^{-2}$ & -1.2 & $1.0 \times 10^{-3}$ & -0.5 & $1.4 \times 10^{-3}$ & 680451 & Nrbp2 & nuclear receptor binding protein 2 \\
\hline-0.2 & $6.1 \times 10^{-1}$ & -0.4 & $1.0 \times 10^{-2}$ & -0.6 & $2.5 \times 10^{-4}$ & -0.5 & $3.4 \times 10^{-3}$ & 94267 & Nudt4 & $\begin{array}{l}\text { nudix (nucleoside diphosphate linked } \\
\text { moiety X)-type motif } 4\end{array}$ \\
\hline 1.0 & $1.6 \times 10^{-2}$ & 0.7 & $4.2 \times 10^{-2}$ & 0.7 & $4.6 \times 10^{-3}$ & 1.2 & $1.9 \times 10^{-5}$ & 171564 & Pbld & $\begin{array}{l}\text { phenazine biosynthesis-like protein domain } \\
\text { containing }\end{array}$ \\
\hline 0.4 & $4.5 \times 10^{-2}$ & 0.3 & $4.2 \times 10^{-2}$ & 0.4 & $7.6 \times 10^{-3}$ & 0.4 & $1.5 \times 10^{-3}$ & 308061 & Pdcd6 & programmed cell death 6 \\
\hline 0.7 & $5.1 \times 10^{-3}$ & 0.7 & $2.0 \times 10^{-4}$ & 0.4 & $1.1 \times 10^{-1}$ & 0.7 & $1.3 \times 10^{-2}$ & 114209 & Phyh & phytanoyl-CoA 2-hydroxylase \\
\hline 0.6 & $1.6 \times 10^{-2}$ & 0.4 & $5.2 \times 10^{-2}$ & 0.5 & $2.7 \times 10^{-3}$ & 0.8 & $7.7 \times 10^{-5}$ & 64390 & Prpsap1 & $\begin{array}{l}\text { phosphoribosyl pyrophosphate synthetase- } \\
\text { associated protein } 1\end{array}$ \\
\hline-0.3 & $3.3 \times 10^{-1}$ & -0.4 & $7.0 \times 10^{-2}$ & -0.6 & $4.3 \times 10^{-3}$ & -0.5 & $2.9 \times 10^{-3}$ & 315655 & $R d x$ & radixin \\
\hline-0.2 & $1.2 \times 10^{-1}$ & -0.4 & $1.5 \times 10^{-2}$ & -0.6 & $5.0 \times 10^{-3}$ & -0.5 & $1.3 \times 10^{-3}$ & 363160 & RGD1311563 & $\begin{array}{l}\text { similar to Oligosaccharyl transferase } 3 \\
\text { CG7748-PA }\end{array}$ \\
\hline 0.1 & $3.1 \times 10^{-1}$ & 0.2 & $1.1 \times 10^{-1}$ & 1.4 & $7.3 \times 10^{-3}$ & 0.7 & $4.1 \times 10^{-4}$ & 315611 & $\operatorname{Scn} 4 b$ & sodium channel, type IV, beta \\
\hline-0.3 & $3.7 \times 10^{-1}$ & -0.6 & $2.9 \times 10^{-2}$ & -1.2 & $6.8 \times 10^{-4}$ & -0.9 & $5.1 \times 10^{-3}$ & 25216 & Sdc1 & syndecan 1 \\
\hline 0.4 & $8.4 \times 10^{-2}$ & 0.4 & $2.3 \times 10^{-2}$ & 0.5 & $4.3 \times 10^{-3}$ & 0.6 & $7.9 \times 10^{-3}$ & 680891 & Sf3b5 & splicing factor $3 b$, subunit 5 \\
\hline-0.2 & $5.9 \times 10^{-1}$ & -0.3 & $3.5 \times 10^{-2}$ & -0.5 & $2.5 \times 10^{-4}$ & -0.4 & $2.6 \times 10^{-3}$ & 81536 & Sgpp1 & sphingosine-1-phosphate phosphatase 1 \\
\hline-0.8 & $2.1 \times 10^{-2}$ & -0.6 & $5.0 \times 10^{-2}$ & -0.7 & $4.2 \times 10^{-4}$ & -0.7 & $2.0 \times 10^{-3}$ & 79111 & Slc27a5 & $\begin{array}{l}\text { solute carrier family } 27 \text { (fatty acid } \\
\text { transporter), member } 5\end{array}$ \\
\hline 0.6 & $2.1 \times 10^{-2}$ & 0.4 & $1.7 \times 10^{-2}$ & 0.5 & $4.4 \times 10^{-3}$ & 0.7 & $3.7 \times 10^{-4}$ & 500707 & $T c 2 n$ & tandem C2 domains, nuclear \\
\hline 0.2 & $4.4 \times 10^{-1}$ & 0.3 & $5.0 \times 10^{-2}$ & 0.3 & $7.0 \times 10^{-3}$ & 0.5 & $3.0 \times 10^{-3}$ & 367909 & Tceal8 & transcription elongation factor A (SII)-like 8 \\
\hline-0.2 & $3.7 \times 10^{-1}$ & -0.3 & $8.3 \times 10^{-2}$ & -0.5 & $3.3 \times 10^{-3}$ & -0.4 & $3.4 \times 10^{-3}$ & 170907 & Tpo1 & developmentally regulated protein TPO1 \\
\hline 0.7 & $2.2 \times 10^{-2}$ & 0.3 & $7.4 \times 10^{-2}$ & 0.6 & $7.5 \times 10^{-3}$ & 0.6 & $4.1 \times 10^{-3}$ & 362890 & Tspan31 & tetraspanin 31 \\
\hline-0.2 & $3.8 \times 10^{-1}$ & -0.1 & $7.8 \times 10^{-1}$ & -0.4 & $6.3 \times 10^{-3}$ & -0.4 & $3.4 \times 10^{-3}$ & 362696 & Ttc7 & tetratricopeptide repeat domain 7 \\
\hline-0.1 & $7.8 \times 10^{-1}$ & -0.3 & $6.2 \times 10^{-2}$ & -0.5 & $5.4 \times 10^{-3}$ & -0.5 & $4.5 \times 10^{-3}$ & 363869 & Ubl3 & ubiquitin-like 3 \\
\hline-0.9 & $1.5 \times 10^{-1}$ & -0.5 & $2.9 \times 10^{-1}$ & -0.9 & $1.5 \times 10^{-4}$ & -1.1 & $1.3 \times 10^{-3}$ & 117522 & Xpnpep2 & $\begin{array}{l}\text { X-prolyl aminopeptidase (aminopeptidase } \\
\text { P) 2, membrane-bound }\end{array}$ \\
\hline 0.3 & $4.6 \times 10^{-2}$ & 0.4 & $1.2 \times 10^{-2}$ & 0.6 & $1.3 \times 10^{-3}$ & 0.7 & $4.3 \times 10^{-3}$ & 360389 & Zfp422 & zinc finger protein 422 \\
\hline
\end{tabular}

Transcriptional responses after 19 hours TCDD exposure in the four rat strains/lines were identified using Affymetrix RAE230A arrays followed by data pre-processing and statistical testing using linear models. Type-Il genes were identified as those where both strains/lines in one collective showed statistically significant responses to TCDD ( $p_{a d j u s t e d}<0.01$ ) in the same direction, while both strains/lines in the other collective showed no response ( $\left.p_{\text {adjusted }}>0.01\right)$. For each strain/line, the fold-change (FC in $\log _{2}$ space) in mRNA levels between treated and control rats as well as the significance levels are presented. Genes are sorted alphabetically by gene symbol. 


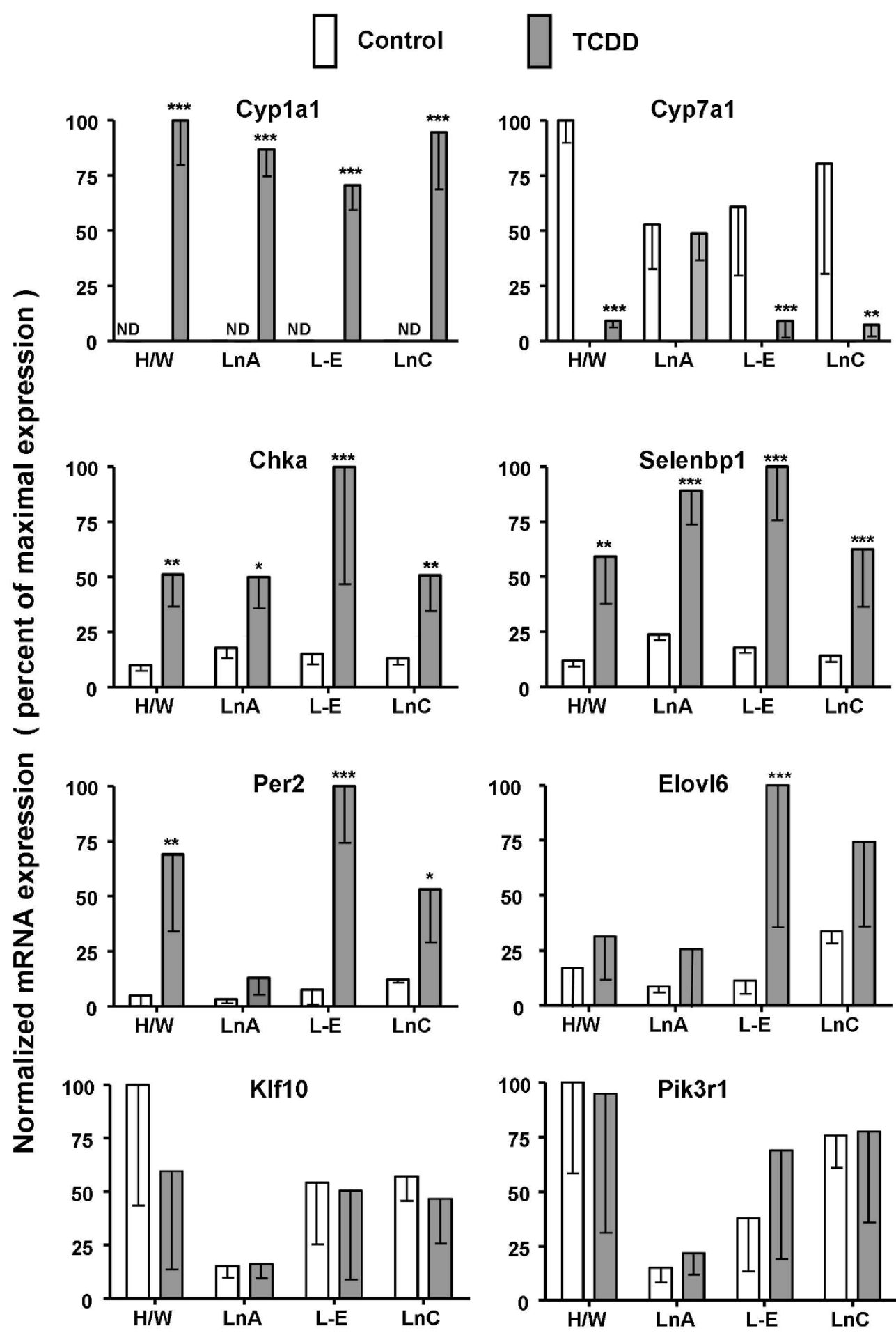

Figure 4 Gene responses to TCDD exposure in livers of dioxin-resistant and dioxin-sensitive rats: measurement of selected mRNA levels by real-time RT-PCR. Hepatic RNA was prepared from male adult TCDD-sensitive rats ( $L$-E and $L n C$ ) and TCDD-resistant rats (H/W and LnA) after 19-hour treatment with a single dose of $100 \mu \mathrm{g} / \mathrm{kg}$ TCDD or corn-oil vehicle control by gavage. mRNA levels were measured by real-time RT-PCR and normalized as described in Materials \& Methods. For each gene, the mRNA level that was highest for any strain/line or treatment was set at 100\% and all other mRNA levels for that gene are shown as a percentage of that maximal level. All results plotted represent the mean \pm standard deviation of four rats. Asterisks indicate significant differences in mRNA levels between control and TCDD-treated rats (t-test; two-tailed, unequal variance, ${ }^{*} p<0.05,{ }^{* *} p<$ $0.01,{ }^{* * *} p<0.001$ ). Note: levels of CYP1A1 mRNA in control animals were below detection limits (ND). 


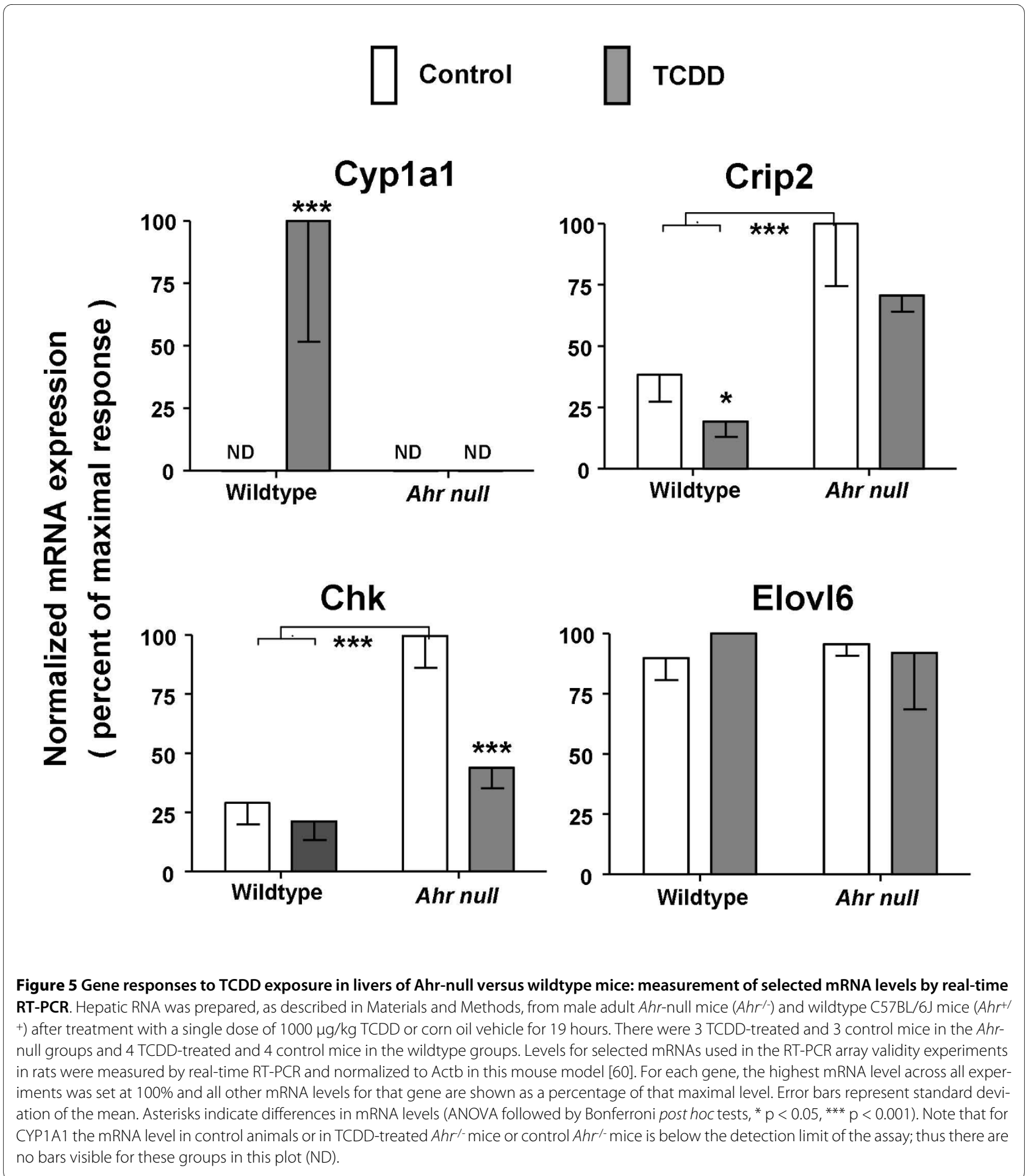

The cause of TCDD-induced wasting and ultimate death as well as the key target tissue(s) remain elusive. Since TCDD causes extensive hepatotoxicity in TCDDsensitive rats (but not in the TCDD-resistant strains), it is reasonable that examination of mechanisms which produce hepatotoxicity may provide clues to mechanisms of wasting and lethality. To this end, we identified 46 TypeII hepatic genes whose TCDD-responsiveness differed between TCDD-resistant and TCDD-sensitive rats. Pathway analysis indicated that these genes are mainly involved in lipid-metabolism, cellular membrane function and energy metabolism (Table 4). These Type-II 
(A)

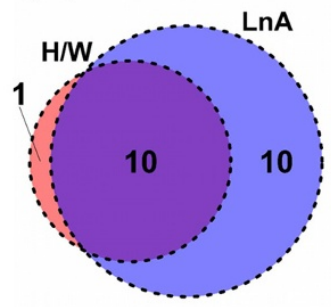

(B)

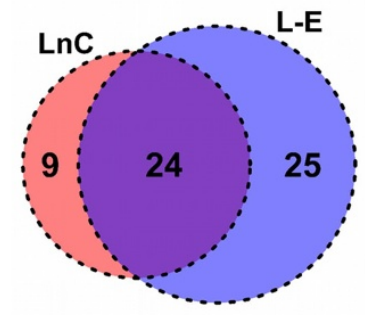

(C)

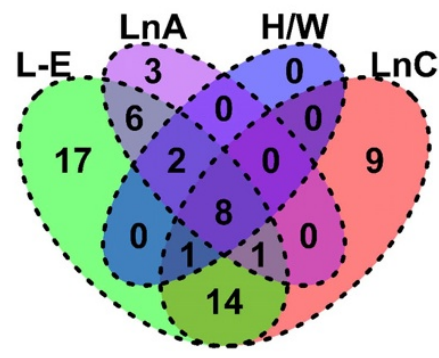

Figure 6 Overlap of functional terms between rat strains/lines. Gene Ontology (GO) analysis was used to determine if different combinations of strains/lines led to alterations in mRNA levels for functionally coherent groups of genes. The gene-lists for each of the four strains/lines were tested for enrichment of each GO category represented on the RAE230A array. False-discovery rates were calculated with 1000 permutations of the dataset using the High-Throughput GoMiner software and a threshold of 5\% FDR was applied. The vast majority of $\mathrm{GO}$ terms enriched in both the resistant $(\mathrm{A})$ and the sensitive (B) strains/lines overlap. A four-way overlap of all strains/lines shows significant overlap, but also some strain-specific responses (C).

genes potentially explain why there are greater manifestations of hepatotoxicity in sensitive rats than in resistant rats; for example, a dramatic accumulation of fatty acids (steatosis) and initial liver hypertrophy which switches to atrophy $\sim 1$ week later (refer to [24] for exhaustive list of hepatotoxic responses). Pohjanvirta et al. [24], in biochemical studies, found that exposure of sensitive rats to TCDD led to steatosis, hypertrophy, liver failure, wasting and eventual death, possibly as the consequence of derailment of energy metabolism due to alterations of (i) lipid homeostasis, (ii) protein metabolism and/or (iii) ATP production/utilization.

\section{(i) Alteration of lipid homeostasis}

In sensitive rats only, we previously observed steatosis with the accumulated fatty acids probably originating from redistribution of peripheral fat deposits to liver rather than from increased lipid synthesis within the liver [42]. This is consistent with our current transcriptomic study in which transcripts related to lipid synthesis were not increased. TCDD-induced suppression of hepatic lipid lipogenesis previously has been reported $[16,17,43]$.

Pathway analysis indicated that genes involved in the lipid metabolism process were enriched in the Type-II gene list. Of particular interest was the decreased expression of $H s d 11 b 1$ and Slc27a5 only in sensitive rats. $H s d 11 b 1$ functions in steroid metabolism and colocalizes with the glucocorticoid receptor where it acts as a local amplifier of corticoid responses including the regulation of fuel metabolism during starvation and stress [44,45]. $H s d 11 b 1$ deficiencies in rodents increase energy expenditure, decrease weight gain with chronic high fat feeding, increase weight loss, increase hepatic lipid oxidation while decreasing lipolysis in adipose tissue and display many metabolic deficiencies $[45,46]$. Slc27a5 encodes a transporter of long-chain fatty acids into the liver where it is exclusively expressed. Its deletion results in increased de novo biosynthesis of long-chain fatty acids in liver due to inhibited uptake of them. Interestingly, in knockout mice, feed intake is depressed, energy expenditure increased and weight gain suppressed $[47,48]$. While further study of these genes is warranted, genes that alter lipid homeostasis may be important in hepatotoxicity and could be involved in pro-death pathways in sensitive rats exposed to TCDD.

\section{(ii) Altered protein metabolism}

In the short term, protein catabolism can be a beneficial response to provide amino acids for energy and maintenance of obligatory functions. However, sustained protein catabolism eventually leads to wasting and mortality. Our current study found that TCDD increased expression of genes that facilitate protein breakdown (Derl1, Derl2 and Mug1) but also decreased the expression of Ass1, the key enzyme in the urea cycle. Deficiencies in Ass1 may disrupt the urea cycle resulting in increased accumulation of amino acids, highly toxic ammonia and other toxic byproducts. TCDD previously has been shown to decrease the expression of the Ass 1 gene after 24 hour exposure [17]. Increased protein breakdown and deficiencies in the urea cycle are consistent with previous reports of elevated plasma levels of most amino acids and decreased plasma urea in sensitive rats but not in resistant rats 6 days after TCDD exposure [49]. In addition, alteration of the balance between protein synthesis versus protein degradation is a key mechanism in switching hepatocytes from hypertrophy to atrophy, as observed in sensitive rats $\sim 1$ week after TCDD exposure [24] and reported for other wasting diseases (e.g. diabetes and cancer cachexia) [50]. Thus, specific genes involved in protein homeostasis are likely important in TCDD-mediated pro-survival pathways.

\section{(iii) Impaired ATP production/utilization}

Derailment of energy metabolism due to impaired ATP production or utilization potentially contributes to manifestations of major TCDD toxicities. After TCDD exposure in sensitive rats, compensatory mechanisms may attempt to increase energy for metabolism by increasing expression of the Atp $5 c 1$ gene that resides within the ATP 
Table 4: Enrichment of functional terms within Type-I response and Type-II response gene lists from rat strains/lines

\begin{tabular}{|c|c|c|c|c|c|}
\hline \multirow[b]{2}{*}{ GO ID } & \multicolumn{2}{|c|}{ Type-I } & \multicolumn{2}{|c|}{ Type-II } & \multirow[b]{2}{*}{ Functional term } \\
\hline & Enrichment & FDR & Enrichment & FDR & \\
\hline GO:0042175 & 2.20 & 1.00 & 2.68 & 0.00 & $\begin{array}{l}\text { nuclear envelope-endoplasmic reticulum } \\
\text { network }\end{array}$ \\
\hline GO:0005789 & 2.23 & 1.00 & 2.71 & 0.00 & endoplasmic reticulum membrane \\
\hline GO:0044432 & 2.06 & 1.00 & 2.54 & 0.00 & endoplasmic reticulum part \\
\hline GO:0044255 & 1.44 & 1.00 & 2.21 & 0.01 & cellular lipid metabolic process \\
\hline GO:0006629 & 1.28 & 1.00 & 2.05 & 0.01 & lipid metabolic process \\
\hline GO:0005783 & 1.63 & 1.00 & 1.99 & 0.01 & endoplasmic reticulum \\
\hline GO:0012505 & 1.07 & 1.00 & 1.84 & 0.02 & endomembrane system \\
\hline GO:0031090 & 0.55 & 1.00 & 1.57 & 0.02 & organelle membrane \\
\hline GO:0031301 & NA & 1.00 & 3.70 & 0.02 & integral to organelle membrane \\
\hline GO:0031300 & NA & 1.00 & 3.57 & 0.02 & intrinsic to organelle membrane \\
\hline GO:0030176 & NA & 1.00 & 4.46 & 0.02 & $\begin{array}{l}\text { integral to endoplasmic reticulum } \\
\text { membrane }\end{array}$ \\
\hline GO:0031227 & NA & 1.00 & 4.25 & 0.03 & $\begin{array}{l}\text { intrinsic to endoplasmic reticulum } \\
\text { membrane }\end{array}$ \\
\hline GO:0003824 & 0.86 & 0.48 & 0.82 & 0.05 & catalytic activity \\
\hline GO:0016491 & 2.69 & 0.02 & 1.94 & 0.03 & oxidoreductase activity \\
\hline GO:0016712 & 5.06 & 0.01 & 3.37 & 0.28 & $\begin{array}{l}\text { oxidoreductase activity acting on paired } \\
\text { donors with incorporation or reduction of } \\
\text { molecular oxygen reduced flavin or } \\
\text { flavoprotein as one donor and } \\
\text { incorporation of one atom of oxygen }\end{array}$ \\
\hline GO:0020037 & 4.04 & 0.01 & 1.93 & 0.72 & heme binding \\
\hline GO:0046906 & 4.04 & 0.01 & 1.93 & 0.72 & tetrapyrrole binding \\
\hline GO:0004497 & 4.42 & 0.02 & 2.31 & 0.59 & monooxygenase activity \\
\hline
\end{tabular}

Gene Ontology (GO) analysis was used to determine if genes exhibiting Type-I (dioxin-responsive across both collectives) or Type-II (dioxinresponsive in only one collective) character were functionally coherent. Lists of Type-I and Type-II genes generated as described in the Results were tested for enrichment of each GO category represented on the RAE230A array. False-discovery rates (FDR) were calculated with 1000 permutations of the dataset using the High-Throughput GoMiner software, bolding highlights those terms with a FDR $<5 \%$. Enrichment values are expressed in $\log _{2}$-space (i.e. a value of 3.0 indicates an 8-fold enrichment). Note that GO:0016491 (oxidoreductase activity) is enriched in both the Type-I and Type-II gene lists.

synthesis pathway and is down-regulated in obese subjects [51]. However, TCDD decreased expression levels of Adk which catalyzes the inter-conversion of adenine nucleotides, and plays an important role in cellular energy homeostasis (2 ADP ATP + AMP); this downregulation may impair use of ATP as an energy source in sensitive rats. Specifically, Adk impairment leads to deficiencies in adenosine nucleotides, including ATP, likely leading to reduced mitochondrial metabolic capacity and impairment of lipid metabolism critical for energy production [52]. Moreover, $A d k$-deficient mice display hepatic steatosis within 4 days and die within 14 days with fatty liver [52]. Thus, deficiencies in adenosine metabolism are powerful contributors to development of hepatic steatosis and development of lethal fatty liver, processes that are also provoked by TCDD in sensitive rats.

In dioxin-resistant rats, where TCDD does not cause severe hepatotoxicity, wasting or death, there was no alteration of mRNA levels for genes which might derail energy metabolism due to alterations of in the homeostasis of lipids, protein metabolism or ATP production/utilization. Only three genes responded to TCDD in the resistant collective but not in the sensitive collective. Two of these three genes function in lipid metabolism: the expression of Phyh was increased while that of Hacl1 was decreased. The third gene Il1rl, whose levels were increased by TCDD, is a receptor whose responsiveness regulates several biological functions, including adaptive and innate immunity, control of programmed cell death 
and stress response [53]. The consequences of altered regulation of these genes in mediating potential pro-survival pathways in response to TCDD warrants further investigation.

\section{Conclusion}

The mechanisms of dioxin-induced toxicities remain elusive but our transcriptomic approach in an in vivo rat model where there are major phenotypic differences in the toxic response is providing clues to the early events that may trigger toxicity. Compelling evidence shows that the transcriptional activity of the AHR is essential for toxicity. Because altered transcription is central to TCDD toxicity, our group and others have profiled changes of mRNA abundance resulting from exposure to TCDD in several model systems. The results are remarkable: TCDD induces wide-spread alterations in mRNA abundance, but only a very small fraction of these changes are conserved between mouse or rat and, as demonstrated here, within different rat strains. Only $31.9 \%$ of dioxinresponsive genes are altered in more than one of the four rat strains/lines.

This diversity of transcriptional responses makes it challenging to identify specific genes responsible for lethality and other major forms of dioxin toxicity. Our results suggest that hepatic toxicity probably is not caused by dysregulation of a single critical gene. Rather, pathways such as lipid metabolism or energy metabolism may be derailed by altered transcription of multiple genes, possibly under coordinate control of the AHR with participation of other regulatory factors. Pathways and individual genes highlighted here are worthy candidates for further mechanistic studies to test their role in mediating or protecting from major dioxin toxicities.

\section{Methods}

\section{Animals and Treatments for Rat Model}

We studied two dioxin-sensitive rat strains/lines expressing wildtype AHR: Long-Evans (Turku/AB) (L-E) and Line-C (LnC). We also studied two dioxin-resistant rat strains/lines expressing the Han/Wistar variant AHR: Han/Wistar (Kuopio) (H/W) and Line-A (LnA) [25]. All animals were males 10-12 weeks of age from breeding colonies of the National Institute for Health and Welfare, Kuopio, Finland. They were housed in groups of 4 (an entire treatment group per cage) in suspended stainlesssteel wire-mesh cages with pelleted R36 feed (Lactamin, Stockholm, Sweden) and tap water available ad libitum. The temperature in the animal room was $21 \pm 1^{\circ} \mathrm{C}$, relative humidity $50 \pm 10 \%$, and a 12 hour-light/12 hour-dark cycle. Study plans were approved by the Animal Experiment Committee of the University of Kuopio and the Provincial Government of Eastern Finland. There were four rats per treatment group. Liver was harvested between
8:30 and 11:00 from rats treated by gavage with a single $100 \mu \mathrm{g} / \mathrm{kg}$ dose of TCDD or corn oil vehicle 19 hours previously. The single dose of $100 \mu \mathrm{g} / \mathrm{kg}$ TCDD produces hepatotoxicity, wasting and death in sensitive rats but not in resistant rats.

\section{Animals and Treatment for Mouse Model}

Liver tissues were from mice in which we previously mapped AHR-dependent and dioxin-dependent gene batteries by transcriptomic analysis [20]. Briefly, male Ahr-null $\left(A h r^{--}\right)$mice in a C57BL/6J background (10 weeks old) and C57BL/6 mice carrying wildtype $\left(A h r^{+/+}\right)$ (15 weeks old) were given a single dose of $1000 \mu \mathrm{g} / \mathrm{kg}$ TCDD or corn oil vehicle by gavage. Liver was harvested 19 hours after treatment. The single dose of TCDD is lethal to wild-type but not $A h r$-null mice and is equitoxic to that given to sensitive rats. We tested 3 TCDD-treated and 3 control mice in the Ahr/- groups and 4 TCDDtreated and 4 control mice in the $A h^{+/+}$groups.

\section{RNA Extraction}

Total RNA was extracted using Qiagen RNeasy kits according to the manufacturer's instructions (Qiagen, Mississauga, Canada). Total RNA yield was quantified by UV spectrophotometry and RNA integrity was verified using an Agilent 2100 BioAnalyzer (Agilent Technologies, Santa Clara, CA).

\section{Microarray analysis}

Sample labeling and hybridization to Affymetrix RAE230A GeneChips were performed by The Centre for Applied Genomics (Toronto, Canada) according to the manufacturer's protocols. At each condition four separate animals were profiled, each on an individual RAE230A microarray. Raw array data were examined for spatial and distributional heterogeneity and differential RNA degradation; no arrays were excluded. Array data were loaded into the R statistical environment (v2.9.2) using the affy package (v1.22.1) of the BioConductor open-source library [54]. Array data were pre-processed with the RMA algorithm [55]. Raw and pre-processed array data are available in the Gene Expression Omnibus repository at NCBI (accession GSE10083). An alternative CDF package was used to ensure each ProbeSet was mapped to a single unique Entrez Gene ID (rae230arnentrezgcdf v12.0.0) [56].

\section{Statistical analysis of array data}

The experimental design employed independent pairwise analyses between treated and control animals for each strain/line (Figure 1). Following quality control and pre-processing of the microarray data, we performed a general linear modeling analysis. For each gene and each strain we determined the magnitude of differential signal intensity between TCDD-exposed and vehicle-treated 
animals. Gene-lists were derived separately for each strain using the limma package (v2.18.3) in the R statistical environment (v2.9.2) with a condition-specific design matrix and within-strain pair-wise contrasts. An empirical Bayes moderation of the standard error [57] and falsediscovery rate control of multiple-testing were applied [58]. A significance threshold of $\mathrm{p}_{\text {adjusted }}<0.01$ was applied to each contrast. We then scored each gene using a scheme described previously [30]. Briefly, each gene was classified as unaltered (Score: 0 ), statistically significantly repressed by TCDD (Score: -1 ), or statistically significantly induced by TCDD (Score: +1$)$ in each strain, and these strain-wise scores were summed.

Unsupervised machine-learning was performed using divisive hierarchical clustering with complete linkage in the $\mathrm{R}$ statistical environment (v2.9.2) using the cluster package (v1.12.1). Pearson's correlation was used as a similarity metric and within-row scaling was performed. Venn diagrams were produced using custom $\mathrm{R}$ code. $\mathrm{R}$ visualizations employed the lattice (v0.17-26) and latticeExtra (v0.6-3) packages.

\section{Functional characterization of responsive genes}

To determine if genes perturbed by TCDD are enriched for specific Gene Ontology (GO) terms, we first identified groups of genes dysregulated by TCDD within each strain/line $\left(\mathrm{p}_{\text {adjusted }}<0.01\right)$. Then GO terms enriched in these groups were identified using the GoMiner tool [59]. False-discovery rates (FDRs) were estimated using 1000 permutations. Rat-specific annotations were used. GO terms with false-discovery rates below $5 \%$ were included in subsequent analyses.

\section{mRNA quantitation by Real-Time RT-PCR}

Total RNA $(2 \mu \mathrm{g})$ was reverse-transcribed into cDNA using oligo-dT primer $\mathrm{p}(\mathrm{dT}) 15$ (Roche Applied Science, Laval, QC, Canada) and Superscript II RNA polymerase according to the manufacturer's instructions (Invitrogen, Carlsbad, CA). Real-time PCR was performed using inhouse designed primers (with 5 ' fluorogenic probes, as described previously [30]) or Applied Biosystems gene expression assays, as described by the manufacturer (Applied Biosystems, Forest City, CA). Primer/probe sequences are in Additional File 2.

Normalized expression was calculated as $2^{-\Delta \Delta C t}$, where $C_{\mathrm{t}}$ is the threshold cycle for detecting fluorescence. PCR amplification efficiency was determined from a 10 -fold serial dilution of a cDNA pool; efficiency ranged from 90$110 \%$ for all genes. Data were normalized to either Actb or Gapdh, genes we previously showed to be suitable as normalization standards for dioxin studies [60]. In the rat model, significant differences in mRNA levels were determined using t-tests (two-tailed, unequal variance). Significant differences in mRNA levels in the $A h r$-null mouse model were identified using analysis of variance (ANOVA) with Bonferroni post hoc tests (GraphPad version 4.0).

\section{Additional material}

Additional file 1 Complete Microarray Results. This file gives a list of all genes interrogated on the microarray, their annotation, and their changes in signal-intensity in each rat strain.

Additional file $\mathbf{2}$ Primer and Probe Sequences. This file lists all primer and probe sequences used for RT-PCR analyses.

\section{Authors' contributions}

The project was conceived and designed by ABO and RP. Animal treatment was performed by RP. mRNA extraction and RT-PCR analyses were performed by IDM. Microarray data and functional analyses were performed by PCB. Microarray data visualization was performed by PCB and HC. IDM wrote the first draft of the manuscript, which PCB, ABO and RP edited and all authors approved.

\section{Acknowledgements}

The authors thank Ms. Ulla Naukkarinen and Mr. Janne Korkalainen for excellent technical assistance. This work was financially supported by grant number MOP57903 from the Canadian Institutes of Health Research (to ABO and PCB) and grant number 123345 from the Academy of Finland to RP. The funding agencies had no role in study design, in collection or interpretation of data, in the writing of the manuscript or the decision to submit the manuscript for publication.

\section{Author Details}

1Department of Pharmacology and Toxicology, University of Toronto, Toronto, Canada, 2Department of Food Hygiene and Environmental Health, Faculty of Veterinary Medicine, University of Helsinki, Helsinki, Finland, ${ }^{3}$ National Institute for Health and Welfare, Laboratory of Toxicology, Kuopio, Finland and ${ }^{4}$ Ontario Institute for Cancer Research, Toronto, Canada

Received: 10 July 2009 Accepted: 26 April 2010

Published: 26 April 2010

\section{References}

1. Okey AB: An Aryl Hydrocarbon Receptor Odyssey to the Shores of Toxicology: The Deichmann Lecture, International Congress of Toxicology-XI. Toxico/ Sci 2007, 98(1):5-38.

2. Mimura J, Yamashita K, Nakamura K, Morita M, Takagi TN, Nakao K, Ema M, Sogawa K, Yasuda M, Katsuki M, et al:: Loss of teratogenic response to 2,3,7,8-tetrachlorodibenzo-p-dioxin (TCDD) in mice lacking the Ah (dioxin) receptor. Genes Cells 1997, 2(10):645-654.

3. Peters JM, Narotsky MG, Elizondo G, Fernandez-Salguero PM, Gonzalez FJ, Abbott BD: Amelioration of TCDD-induced teratogenesis in aryl hydrocarbon receptor (AhR)-null mice. Toxicol Sci 1999, 47(1):86-92.

4. Bunger MK, Moran SM, Glover E, Thomae TL, Lahvis GP, Lin BC, Bradfield CA: Resistance to 2,3,7,8-Tetrachlorodibenzo-p-dioxin Toxicity and Abnormal Liver Development in Mice Carrying a Mutation in the Nuclear Localization Sequence of the Aryl Hydrocarbon Receptor. $J$ Biol Chem 2003, 278(20):17767-17774.

5. Walisser JA, Bunger MK, Glover E, Harstad EB, Bradfield CA: Patent ductus venosus and dioxin resistance in mice harboring a hypomorphic Arnt allele. J Biol Chem 2004, 279(16):16326-16331.

6. Bunger MK, Glover E, Moran SM, Walisser JA, Lahvis GP, Hsu EL, Bradfield CA: Abnormal Liver Development and Resistance to 2,3,7,8Tetrachlorodibenzo-p-dioxin Toxicity in Mice Carrying a Mutation in the DNA Binding Domain of the Aryl Hydrocarbon Receptor. Toxicol Sci 2008, 106:83-92.

7. Hankinson O: The aryl hydrocarbon receptor complex. Annu Rev Pharmacol Toxicol 1995, 35:307-340.

8. Whitlock JP Jr: Mechanistic aspects of dioxin action. Chem Res Toxicol 1993, 6(6):754-763. 
9. Ma Q: Induction of CYP1A1. The AhR/DRE paradigm: transcription, receptor regulation, and expanding biological roles. Curr Drug Metab 2001, 2:149-164

10. Denison MS, Fisher JM, Whitlock JP Jr: The DNA recognition site for the dioxin-Ah receptor complex. Nucleotide sequence and functional analysis. J Biol Chem 1988, 263(33):17221-17224

11. Sogawa K, Numayama-Tsuruta K, Takahashi T, Matsushita N, Miura C, Nikawa J, Gotoh O, Kikuchi Y, Fujii-Kuriyama Y: A novel induction mechanism of the rat CYP1A2 gene mediated by Ah receptor-Arnt heterodimer. Biochem Biophys Res Commun 2004, 318(3):746-755.

12. Boutros PC, Moffat ID, Franc MA, Tijet N, Tuomisto J, Pohjanvirta R, Okey $A B$ : Dioxin-responsive AHRE-II gene battery: identification by phylogenetic footprinting. Biochem Biophys Res Commun 2004, 321(3):707-715

13. Okey AB, Boutros PC, Harper PA: Polymorphisms of human nuclear receptors that control expression of drug-metabolizing enzymes. Pharmacogenet Genomics 2005, 15(6):371-379.

14. Vezina CM, Walker NJ, Olson JR: Subchronic exposure to TCDD, PeCDF, PCB126, and PCB153: effect on hepatic gene expression. Environ Health Perspect 2004, 112(16):1636-1644.

15. Boverhof DR, Burgoon LD, Tashiro C, Chittim B, Harkema JR, Jump DB, Zacharewski TR: Temporal and dose-dependent hepatic gene expression patterns in mice provide new insights into TCDD-mediated hepatotoxicity. Toxicol Sci 2005, 85:1048-1063.

16. Boverhof DR, Burgoon LD, Tashiro C, Sharratt B, Chittim B, Harkema JR, Mendrick DL, Zacharewski TR: Comparative toxicogenomic analysis of the hepatotoxic effects of TCDD in Sprague Dawley rats and C57BL/6 mice. Toxicol Sci 2006, 94(2):398-416.

17. Fletcher N, Wahlstrom D, Lundberg R, Nilsson CB, Nilsson KC, Stockling K, Hellmold H, Hakansson H: 2,3,7,8-Tetrachlorodibenzo-p-dioxin (TCDD) alters the mRNA expression of critical genes associated with cholesterol metabolism, bile acid biosynthesis, and bile transport in rat liver: A microarray study. Toxicol Appl Pharmacol 2005, 207(1):1-24.

18. Hayes KR, Bradfield CA: Advances in toxicogenomics. Chem Res Toxicol 2005, 18(3):403-414

19. Ovando BJ, Vezina CM, McGarrigle BP, Olson JR: Hepatic gene downregulation following acute and subchronic exposure to $2,3,7,8$ tetrachlorodibenzo-p-dioxin. Toxicol Sci 2006, 94(2):428-438

20. Tijet N, Boutros PC, Moffat ID, Okey AB, Tuomisto J, Pohjanvirta R: The aryl hydrocarbon receptor regulates distinct dioxin-dependent and dioxinindependent gene batteries. Mol Pharmacol 2006, 69:140-153.

21. Slatter JG, Cheng O, Cornwell PD, de Souza A, Rockett J, Rushmore T, Hartley D, Evers R, He Y, Dai X, et al: Microarray-based compendium of hepatic gene expression profiles for prototypical ADME gene-inducing compounds in rats and mice in vivo. Xenobiotica 2006, 36(1011):902-937.

22. N'Jai A, Boverhof D, Dere E, Burgoon L, Tan Y, Rowlands J, Budinsky R Stebbins K, Zacharewski T: Comparative Temporal Toxicogenomic Analysis of TCDD- and TCDF-Mediated Hepatic Effects in Immature Female C57BL/6 Mice. Toxicol Sci 2008, 103(2):285-97.

23. Boutros PC, Yan R, Pohjanvirta R, Okey AB: Transcriptomic responses to 2,3,7,8-tetrachlorodibenzo-p-dioxin (TCDD) in liver: comparison of rat and mouse. BMC Genomics 2008, 9:

24. Pohjanvirta R, Tuomisto J: Short-term toxicity of 2,3,7,8tetrachlorodibenzo- $p$-dioxin in laboratory animals: effects, mechanisms, and animal models. Pharmacol Rev 1994, 46(4):483-549.

25. Pohjanvirta R, Wong JMY, Li W, Harper PA, Tuomisto J, Okey AB: Point mutation in intron sequence causes altered carboxyl-terminal structure in the aryl hydrocarbon receptor of the most 2,3,7,8tetrachlorodibenzo-p-dioxin-resistant rat strain. Mol Pharmacol 1998, 54(1):86-93

26. Tuomisto JT, Viluksela M, Pohjanvirta R, Tuomisto J: The AH receptor and a novel gene determine acute toxic responses to TCDD: segregation of the resistant alleles to different rat lines. Toxicol Appl Pharmacol 1999, 155(1):71-81

27. Moffat ID, Roblin S, Harper PA, Okey AB, Pohjanvirta R: Aryl hydrocarbon receptor splice variants in the dioxin-resistant rat: tissue expression and transactivational activity. Mol Pharmacol 2007, 72(4):956-966.

28. Pohjanvirta R: Transgenic mouse lines expressing rat $\mathrm{AH}$ receptor variants--a new animal model for research on $\mathrm{AH}$ receptor function and dioxin toxicity mechanisms. Toxicol Appl Pharmacol 2009, 236(2):166-182
29. Niittynen M, Simanainen U, Syrjala P, Pohjanvirta R, Viluksela M, Tuomisto $\mathrm{J}$, Tuomisto JT: Differences in acute toxicity syndromes of 2,3,7,8tetrachlorodibenzo-p-dioxin and 1,2,3,4,7,8-hexachlorodibenzo-pdioxin in rats. Toxicology 2007, 235(1-2):39-51.

30. Franc MA, Moffat ID, Boutros PC, Tuomisto JT, Tuomisto J, Pohjanvirta R, Okey AB: Patterns of dioxin-altered mRNA expression in livers of dioxinsensitive versus dioxin-resistant rats. Arch Toxicol 2008, 82(11):809-830

31. Simanainen U, Tuomisto JT, Tuomisto J, Viluksela M: Structure-activity relationships and dose responses of polychlorinated dibenzo-pdioxins for short-term effects in 2,3,7,8-tetrachlorodibenzo-p-dioxinresistant and -sensitive rat strains. Toxicol Appl Pharmacol 2002, 181(1):38-47.

32. Denison MS, Whitlock JP Jr: Xenobiotic-inducible transcription of cytochrome P450 genes. J Bio/ Chem 1995, 270:18175-18178.

33. Nebert DW, Dalton TP, Okey AB, Gonzalez FJ: Role of aryl hydrocarbon receptor-mediated induction of the CYP1 enzymes in environmental toxicity and cancer. J Biol Chem 2004, 279(23):23847-23850.

34. Fernandez-Salguero P, Pineau T, Hilbert DM, McPhail T, Lee SS, Kimura S, Nebert DW, Rudikoff S, Ward JM, Gonzalez FJ: Immune system impairment and hepatic fibrosis in mice lacking the dioxin-binding Ah receptor [see comments]. Science 1995, 268(5211):722-726.

35. Schmidt JV, Su GH, Reddy JK, Simon MC, Bradfield CA: Characterization of a murine Ahr null allele: involvement of the Ah receptor in hepatic growth and development. Proc Natl Acad Sci USA 1996, 93(13):6731-6736

36. Pohjanvirta R, Viluksela M, Tuomisto JT, Unkila M, Karasinska J, Franc M-A Holowenko M, Giannone JV, Harper PA, Tuomisto J, et al.: Physicochemical differences in the AH receptors of the most TCDD-susceptible and the most TCDD-resistant rat strains. Toxicol Appl Pharmacol 1999, 155(1):82-95.

37. Pohjanvirta $R$, Unkila $M$, Tuomisto J: TCDD-induced hypophagia is not explained by nausea. Pharmacol Biochem Behav 1994, 47(2):273-282.

38. Seefeld MD, Corbett SW, Keesey RE, Peterson RE: Characterization of the wasting syndrome in rats treated with 2,3,7,8-tetrachlorodibenzo- $p$ dioxin. Toxicol Appl Pharmacol 1984, 73(2):311-322

39. Seefeld MD, Keesey RE, Peterson RE: Body weight regulation in rats treated with 2,3,7,8-tetrachlorodibenzo-p-dioxin. Toxicol App/ Pharmacol 1984, 76(3):526-536.

40. Gasiewicz TA, Holscher MA, Neal RA: The effect of total parenteral nutrition on the toxicity of 2,3,7,8-tetrachlorodibenzo-p-dioxin in the rat. Toxicol Appl Pharmacol 1980, 54(3):469-488.

41. Weber LW, Lebofsky M, Stahl BU, Gorski JR, Muzi G, Rozman K: Reduced activities of key enzymes of gluconeogenesis as possible cause of acute toxicity of 2,3,7,8-tetrachlorodibenzo-p-dioxin (TCDD) in rats. Toxicology 1991, 66(2):133-144

42. Pohjanvirta R, Sankari S, Kulju T, Naukkarinen A, Ylinen M, Tuomisto J: Studies on the role of lipid peroxidation in the acute toxicity of TCDD in rats. Pharmacol Toxicol 1990, 66(5):399-408.

43. Sato S, Shirakawa H, Tomita S, Ohsaki Y, Haketa K, Tooi O, Santo N, Tohkin M, Furukawa Y, FJ G, et al: Low-dose dioxins alter gene expression related to cholesterol biosynthesis, lipogenesis, and glucose metabolism through the aryl hydrocarbon receptor-mediated pathway in mouse liver. Toxicology and Applied Pharmacology 2008, 229(1):10-9.

44. Walker BR: Extra-adrenal regeneration of glucocorticoids by 11 betahydroxysteroid dehydrogenase type 1: physiological regulator and pharmacological target for energy partitioning. Proc Nutr Soc 2007, 66(1):1-8.

45. Morton NM, SeckI JR: 11 beta-hydroxysteroid dehydrogenase type 1 and obesity. Front Horm Res 2008, 36:146-164

46. Berthiaume M, Laplante M, Festuccia W, Gelinas Y, Poulin S, Lalonde J, Joanisse DR, Thieringer $R$, Deshaies $Y$ : Depot-specific modulation of rat intraabdominal adipose tissue lipid metabolism by pharmacological inhibition of 11 beta-hydroxysteroid dehydrogenase type 1. Endocrinology 2007, 148(5):2391-2397.

47. Doege H, Baillie RA, Ortegon AM, Tsang B, Wu Q, Punreddy S, Hirsch D, Watson N, Gimeno RE, Stahl A: Targeted deletion of FATP5 reveals multiple functions in liver metabolism: alterations in hepatic lipid homeostasis. Gastroenterology 2006, 130(4):1245-1258

48. Hubbard B, Doege H, Punreddy S, Wu H, Huang X, Kaushik VK, Mozell RL, Byrnes JJ, Stricker-Krongrad A, Chou CJ, et al:: Mice deleted for fatty acid 
transport protein 5 have defective bile acid conjugation and are protected from obesity. Gastroenterology 2006, 130(4):1259-1269.

49. Viluksela M, Unkila M, Pohjanvirta R, Tuomisto JT, Stahl BU, Rozman KK, Tuomisto J: Effects of 2,3,7,8-tetrachlorodibenzo-p-dioxin (TCDD) on liver phosphoenolpyruvate carboxykinase (PEPCK) activity, glucose homeostasis and plasma amino acid concentrations in the most TCDDsusceptible and the most TCDD-resistant rat strains. Arch Toxicol 1999, 73(6):323-336.

50. Tisdale MJ: The ubiquitin-proteasome pathway as a therapeutic target for muscle wasting. J Support Oncol 2005, 3(3):209-217.

51. Pihlajamaki J, Boes T, Kim EY, Dearie F, Kim BW, Schroeder J, Mun E, Nasser I, Park PJ, Bianco AC, et al: Thyroid hormone-related regulation of gene expression in human fatty liver. J Clin Endocrinol Metab 2009, 94(9):3521-3529.

52. Boison D, Scheurer L, Zumsteg V, Rulicke T, Litynski P, Fowler B, Brandner $\mathrm{S}$, Mohler H: Neonatal hepatic steatosis by disruption of the adenosine kinase gene. Proc Natl Acad Sci USA 2002, 99(10):6985-6990.

53. Akira S, Takeda K: Toll-like receptor signalling. Nat Rev Immunol 2004 4(7):499-511.

54. Gentleman RC, Carey VJ, Bates DM, Bolstad B, Dettling M, Dudoit S, Ellis B, Gautier L, Ge Y, Gentry J, et al:: Bioconductor: open software development for computational biology and bioinformatics. Genome Biol 2004, 5(10):R80.

55. Irizarry RA, Bolstad BM, Collin F, Cope LM, Hobbs B, Speed TP: Summaries of Affymetrix GeneChip probe level data. Nucleic Acids Res 2003, 31(4):e15.

56. Dai M, Wang P, Boyd AD, Kostov G, Athey B, Jones EG, Bunney WE, Myers RM, Speed TP, Akil H, et al:: Evolving gene/transcript definitions significantly alter the interpretation of GeneChip data. Nucleic Acids Res 2005, 33(20):e175.

57. Smyth GK: Linear Models and Empirical Bayes Methods for Assessing Differential Expression in Microarray Experiments. Statistical Applications in Genetics and Molecular Biology 2003, 3(1):1-26.

58. Storey JD, Tibshirani R: Statistical significance for genomewide studies. Proc Natl Acad Sci USA 2003, 100(16):9440-9445.

59. Zeeberg BR, Feng W, Wang G, Wang MD, Fojo AT, Sunshine M, Narasimhan S, Kane DW, Reinhold WC, Lababidi S, et al.: GoMiner: a resource for biological interpretation of genomic and proteomic data. Genome Biol 2003, 4(4):R28.

60. Pohjanvirta R, Niittynen M, Linden J, Boutros PC, Moffat ID, Okey AB: Evaluation of various housekeeping genes for their applicability for normalization of mRNA expression in dioxin-treated rats. Chem Biol Interact 2006, 160(2):134-149.

doi: 10.1186/1471-2164-11-263

Cite this article as: Moffat et al., Aryl hydrocarbon receptor (AHR)-regulated transcriptomic changes in rats sensitive or resistant to major dioxin toxicities BMC Genomics 2010, 11:263

Submit your next manuscript to BioMed Centra and take full advantage of:

- Convenient online submission

- Thorough peer review

- No space constraints or color figure charges

- Immediate publication on acceptance

- Inclusion in PubMed, CAS, Scopus and Google Scholar

- Research which is freely available for redistribution

Submit your manuscript at www.biomedcentral.com/submit
C Biomed Central 